\title{
Influence of pelvic inclination on sit to stand task in stroke patients
}

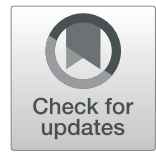

\author{
Moshera Hassan Darwish', Sandra Ahmed ${ }^{2}$, Manar El-sayed Ismail ${ }^{1 *}$ and Heba Ahmed Khalifa ${ }^{1}$
}

\begin{abstract}
Background: Stroke results in an impaired sit to stand (STS) task. Pelvic movements are essential in daily living activities. Few studies investigated the effect of spine and pelvis separately on functional activities in stroke patients.

Objective: The study aimed to assess the angles of pelvic inclination (anterior and posterior pelvic tilt angles) (APT and PPT) during sitting position and during STS movement. It aimed also to determine the influence of sagittal pelvic tilt angles on STS performance in stroke patients.

Patients and methods: Thirty male hemi-paretic stroke patients (Gl) and 15 matched healthy volunteer subjects (GII) represented the sample of this study. Stroke patients were assigned into two equal groups (group la and lb). Sagittal pelvic tilt angles were measured by using the palpation meter inclinometer during sitting position and during initiation and mid of STS by using two dimensional (2D) video-based motion analysis system. Time of five repetitions STS test was used to assess the ability to perform STS task.
\end{abstract}

Results: The results showed a significant increase of PPT angle during static sitting, a significant decrease in APT angle during initiation and mid of STS task and a significant increase in time taken for five repetitions STS test in both stroke groups $(P<0.05)$.

Conclusion: Abnormal pelvic alignment and movements affect the functional performance of stroke patients during sitting and sit to stand task.

Trial registration: NCT03053154. Registered January 22, 2017. Retrospectively registered.

Keywords: Stroke, Sitting, Sit to stand, Pelvic inclination, Sagittal pelvic tilt angles, Anterior pelvic tilt angle, Posterior pelvic tilt angle

\section{Introduction}

Stroke is the third cause of mortality in the world and one of the most common causes of long-term disability [1]. After stroke, patients have limitations of functional activities putting many strains on patients and their caregivers [2]. Sit to stand (STS) task is a complex activity. It involves movement of all body parts from head to foot [3]. The ability to perform STS is an essential skill. It allows the individual to begin locomotion and to interact with the environment [4]. Patients after stroke do not easily regain the ability to stand up safely from a chair [5].

\footnotetext{
*Correspondence: manar.ismail@cu.edu.eg; elmanar_ismail@yahoo.com ${ }^{1}$ Department of Neuromuscular Disorder and Its Surgery, Faculty of Physical Therapy, Cairo University, Cairo 12612, Egypt

Full list of author information is available at the end of the article
}

Pelvic alignment is the cornerstone of overall body alignment. It allows efficient movements' performance and effective muscle recruitment [6]. The trunk including the spine and pelvis acts as a dynamic and stable core from which the upper and lower limbs move. Control of the pelvic motion is important in maintaining whole body balance in different planes [7]. Pelvic movements in lateral and anteroposterior directions are important to weight bearing and transfers. Pelvic movements are also integrated in all functional activities [8]. After stroke, the patient's pelvis becomes unstable [9].

Although, numerous studies analyzed trunk movement during STS task in stroke patients, only few studies addressed the effect of spine and pelvis separately on functional activities in stroke patients. The range of pelvic motion is one of the main factors involved in the STS 
activity, but the influence of pelvic angles was not analyzed during STS movement [10]. There is a crucial need to have a better understanding of the effect of sagittal pelvic tilt angles on STS activity and to know the important factors to be considered to improve the patients' treatment and performance.

\section{Aim of this work}

The aim of the present study was to assess the anterior and posterior pelvic tilt angles in stroke patients during sitting position and to analyze the influence of sagittal pelvic tilt angles on ability to perform STS task during rising from a chair in stroke patients.

\section{Patients and methods}

Thirty male hemi-paretic stroke patients (study group, group I) and fifteen healthy subjects matched in (age, sex, height, weight) (control group, group II) participated in this study. The patients were assigned into two equal groups (group Ia and Ib). Group Ia included the stroke patients with right side affection (right hemiparetic). Group Ib included the stroke patients with left side affection (left hemiparetic). The patients were recruited from the out-patient clinic for neuromuscular disorder and its surgery, Faculty of Physical Therapy, Cairo University and out- patient clinic of El-kasr El- Aini Hospital, Faculty of Medicine, Cairo University.

Patients were included with age ranged from 45 to 60 years, BMI ranged from 18.5 to $24.9 \mathrm{~kg} / \mathrm{m}^{2}$, duration of stroke ranged from 6 months to 2 years. All the patients had ability to maintain sitting position without using any aids and to stand from sitting position five times independently without assistance. The degree of spasticity of paretic lower limb muscles ranged from $(1: 1+)$ according to the Modified Ashworth Scale and the degree of weakness in paretic lower limb muscles was not less than (grade 3) according to group muscle testing. Patients with visual, auditory, vestibular deficits or cognitive impairments, leg length discrepancy more than $0.5 \mathrm{~cm}$, and history of previous strokes or other neurological disorders, any orthopedic problem in back, pelvis, or lower limbs, were excluded.

All patients were subjected to a full clinical neurological assessment. Pelvic inclination was assessed by determining sagittal pelvic tilt angles. Each patient was asked to sit with bare feet crossing arms over chest on armless chair without back support. The chair was chosen with the seat level was $100 \%$ of patients lower leg length with the $90^{\circ}$ knee flexion angle. Sagittal pelvic tilt angles were assessed for right then for left side of each patient during relaxed static sitting position by palpation meter (PALM) inclinometer [11]. Three measurements were recorded, and the mean value was calculated. Anterior pelvic tilt angle (APT) represented as a positive angle and posterior pelvic tilt (PPT) angle represented as a negative angle. Sagittal pelvic tilting angles were assessed for right then for left side of each patient during STS by using 2D video-based motion analysis system [12]. It required reflective markers, digital camera, and special motion analysis software. One reflective marker was attached over the midline of first thoracic spine. Two markers were attached over ASIS and PSIS pelvic landmarks. One marker was placed over the lateral aspect of tested lower limb (2/3 thigh) [13]. A digital camera was positioned at a distance of $6.5 \mathrm{~m}$ [13]. Each patient performed two STS trials at a self-selected pace. Following first trial, the second trial was videotaped. The resultant videotapes for right and left sides of each patient were processed during initiation and mid events of STS [13] by Kinovea ${ }^{\circ}$ software computer program [14]. After accomplished the measurements of pelvic tilt angles, each patient was assessed by five repetitions STS test. The time taken to complete five repetitions of the STS maneuver was recorded by stop watch to assess the ability to perform STS activity [15].

\section{Statistical analysis}

The statistical analysis was done using the Statistical Package of Social Science Software program, version 21 (SPSS, IBM Inc., Chicago, IL). Descriptive statistics were used in the form of arithmetic mean and standard deviation for all variables. Inferential statistics were used in the form of two-way analysis of variance. Mixed design MANOVA test was used to explore where the significant differences occurred between affected side of both stroke groups comparing with corresponding side of control and between two tested sides within each patient in three groups. $P$ value was used to indicate the level of significance $(P<0.05$ was considered significant).

\section{Results}

There was no statistical difference between stroke groups and control regarding general characteristics including age, height, and weight $\left(P^{>} 0.05\right)$.

The results showed a statistically significant increase of posterior pelvic tilt angle during static sitting position of affected sides in both stroke groups compared with control group (Table 1). There was no statistical difference of posterior pelvic tilt angle between two tested sides during static sitting position among the three groups $\left(P^{>} 0.05\right)$.

A statistically significant decrease of anterior pelvic tilt angle showed during initiation and mid of STS movement in both stroke groups compared with control group (Table 2). During initiation and mid of STS movement, there was a statistically significant decrease of anterior pelvic tilt angle of more affected side compared with less affected side of (GIa), while there was no 
Table 1 Mean values of sagittal pelvic tilt angles in degrees $\left(^{\circ}\right)$ of three groups during static sitting by Palpation meter inclinometer

\begin{tabular}{|c|c|c|c|c|c|c|}
\hline \multirow[t]{2}{*}{ Variable } & $\begin{array}{l}\text { Gla } \\
\text { (affected side) }\end{array}$ & $\begin{array}{l}\text { Gll } \\
\text { (right side) }\end{array}$ & \multirow[t]{2}{*}{$\begin{array}{l}P \\
\text { value }\end{array}$} & \multirow{2}{*}{$\begin{array}{l}\text { Glb } \\
\text { (affected side) } \\
\text { Mean } \pm \text { SD }\end{array}$} & $\begin{array}{l}\text { Gll } \\
\text { (left side) }\end{array}$ & \multirow[t]{2}{*}{$\begin{array}{l}P \\
\text { value }\end{array}$} \\
\hline & Mean \pm SD & Mean \pm SD & & & Mean \pm SD & \\
\hline Pelvic tilt from Static sitting $\left({ }^{\circ}\right)$ & $-14.33 \pm 4.35$ & $-11.20 \pm 3.52$ & $0.034^{*}$ & $-16.33 \pm 4.25$ & $-11.47 \pm 3.60$ & $0.002^{*}$ \\
\hline
\end{tabular}

SD Standard deviation, $P$ probability, Significant $P^{*}<0.05,^{\circ}$ Degree

statistical difference between tested sides of both (GIb) and (GII) (Table 3). The results also showed a statistically significant increase of time exerted to accomplish five repetitions STS test in both stroke groups compared with control group (Table 4).

\section{Discussion}

The present study was conducted on male patients as the prevalence of stroke is higher in males more than females in Egypt [16] and worldwide [17]. Major gender differences were shown in the joint angles during phases of sit to stand movement [18]. Also, pelvic alignment was different among never-pregnant, pregnant, and postpartum women [19].

In the current study, the patient's age ranged from 45 to 60 years to eliminate the effect of age on pelvic tilt angles. Maximum anterior and posterior pelvic tilt angles were significantly smaller in participants aged over 60 [20]. The duration of illness was not less than 6 months as the strongest improvements for the execution of STS movement showed during first 3 months post-stroke with a leveling off thereafter [21]. It was not more than 2 years to avoid the influence of disuse atrophy of lower limbs on STS task performance. Obese patients were excluded from this study to eliminate the effect of obesity on sit to stand movement strategy. Obese subjects rise from the chair with limited trunk flexion and with moving their feet backwards from initial position. They showed also higher knee joint torque than hip torque [22]. Patients who had leg length discrepancy more than $0.5 \mathrm{~cm}$ were excluded from the study. Pelvic tilt is considered the most sensitive factor to change due to leg length discrepancy more than $0.5 \mathrm{~cm}$ [23].

The results of the present study showed a significant increase in the posterior pelvic tilt angle during static sitting of both stroke groups compared with control. The results of this study agreed with Martin and Kessler [24]; O'Sullivan and Schmitz [4]; O'Sullivan and colleagues [25]; and Hitoshi and colleagues [10]. The results may be attributed to insufficient co-activation of abdominal and extensor muscles in stroke patients. In the sitting position, weakness of abdominal muscles may make the line of gravity (LOG) placed relatively posterior to the center of gravity (COG) increasing the liability to fall backwards. Stroke patients may compensate by sitting with an excessive flexed thoracic spine to place the LOG anterior to the COG to avoid falling backward during sitting position [26].

Stroke patients may also compensate by sitting with excessive posterior pelvic tilt to increase the passive stability during sitting position. Adequate stabilizing system of the spine is very important to achieve the ideal lumbo-pelvic sitting. The three main stabilizing systems are a passive (osteo-ligamentous system), an active (musculo-tendinous system), and a neural control system [27]. A stroke impairs the latter two sub-systems. Postural muscle activity in stroke patients may be decreased as the lumbo-pelvic region became dependent on the passive structures to maintain the sitting position against gravity.

The results may be also attributed to sitting with excessive flexed thoracic spine in stroke patients may move the pelvis passively into a posterior pelvic tilt. This may lead to an approximation of the attachments of abdominal muscles. This impaired length tension relationship may lead to more asymmetrical weakness.

The results of the current study showed a nonsignificant difference between right and left sides within each patient during static sitting among three groups. This may be attributed to unilateral brain lesion in stroke patients may affect the entire abdominal muscles and influences the position of both ilium bones of the pelvis. Neurologically, trunk muscles are bilaterally innervated. Tanaka and colleagues [28] stated that weakness of trunk muscles in hemiplegic patients resulted from the upper motor neuron lesion and disuse. In

Table 2 Mean values of anterior pelvic tilt angles during initiation and mid of sit to stand task by two dimensional video based motion analysis in (Gla), (Glb), and (GIl)

\begin{tabular}{|c|c|c|c|c|c|c|}
\hline \multirow[t]{2}{*}{ Variables } & $\begin{array}{l}\text { Gla } \\
\text { (affected side) }\end{array}$ & $\begin{array}{l}\text { Gll } \\
\text { (right side) }\end{array}$ & $P$ value & \multirow{2}{*}{$\begin{array}{l}\text { Glb } \\
\text { (affected side) } \\
\text { Mean } \pm \text { SD }\end{array}$} & $\begin{array}{l}\text { Gll } \\
\text { (left side) }\end{array}$ & \multirow[t]{2}{*}{$\begin{array}{l}P \\
\text { value }\end{array}$} \\
\hline & Mean \pm SD & Mean \pm SD & & & Mean \pm SD & \\
\hline Pelvic tilt angle during initiation of STS $\left(^{\circ}\right)$ & $-11.13 \pm 4.85$ & $-7.53 \pm 4.56$ & $0.046^{*}$ & $-11.20 \pm 4.72$ & $-6.87 \pm 4.96$ & $0.021^{*}$ \\
\hline Pelvic tilt angle during mid of STS $\left(^{\circ}\right)$ & $7.87 \pm 4.15$ & $14.13 \pm 3.9$ & $0.0001^{*}$ & $7.60 \pm 5.34$ & $13.80 \pm 3.72$ & $0.001^{*}$ \\
\hline
\end{tabular}

STS Sit to stand, SD Standard deviation, $P$ probability, Significant $P^{*}<0.05,^{\circ}$ degree 
Table 3 Mean values of anterior pelvic tilt angles during initiation and mid of sit to stand task between two tested sides of three groups

\begin{tabular}{|c|c|c|c|c|c|c|}
\hline \multirow[t]{2}{*}{ Variables } & \multicolumn{3}{|c|}{ Pelvic tilt angle during initiation of STS $\left(^{\circ}\right)$} & \multicolumn{3}{|c|}{ Pelvic tilt angle during mid of STS $\left(^{\circ}\right)$} \\
\hline & Right & Left & $P$ value & Right & Left & $P$ value \\
\hline Gla $($ mean $\pm \mathrm{SD})$ & $-11.13 \pm 4.85$ & $-7.87 \pm 3.11$ & $0.037^{*}$ & $7.87 \pm 4.15$ & $10.73 \pm 3.45$ & $0.049^{*}$ \\
\hline Glb (mean $\pm S D)$ & $-9.20 \pm 5.71$ & $-11.20 \pm 4.72$ & 0.305 & $11.00 \pm 4.34$ & $7.60 \pm 5.34$ & 0.066 \\
\hline Gll (mean \pm SD) & $-7.53 \pm 4.56$ & $-6.87 \pm 4.96$ & 0.705 & $14.13 \pm 3.9$ & $13.80 \pm 3.72$ & 0.814 \\
\hline
\end{tabular}

STS Sit to stand, SD Standard deviation, $P$ probability, Significant $P^{*}<0.05,^{\circ}$ Degree

stroke patients, a unilateral upper motor neuron lesion may cause muscle weakness on each side of the trunk. Anatomically, a part from the rectus abdominal muscle and the rest of the abdominal muscles are attached to the linea alba through central aponeurosis fascial expansions bilaterally [9].

During initiation of STS movement, the results of the present study showed a significant decrease of anterior pelvic tilt angle of both stroke groups compared with control. These results agreed with Hitoshi and colleagues [10]. The results may be attributed to inappropriate activation of the trunk muscles. Ideal activation of the trunk muscles occurs when the pelvis is optimally aligned with the trunk. The initial motion in transferring from sitting to standing is the anterior translation of the upper body by flexing the hips. An erect lumbo-pelvic sitting is the ideal starting position to allow the patient's weight to be translated horizontally during preextension phase. Sitting with a posterior pelvic tilt may affect patient's ability to transfer from sitting to standing. Patients attempt to bring the body weight forward by larger trunk forward leaning as the patients flex the hips. This brings the head forward but does not effectively translate the body mass anteriorly to base of support (BOS). From this position, it is difficult to transfer to standing because much of the body weight is still too far posterior. This may cause the patient to lose the balance posteriorly and fall back as attempting to stand up [4].

During mid of STS movement, the results of the current study showed a significant decrease of anterior pelvic tilt angle of both stroke groups compared with control. These results may be attributed to lacking of anterior pelvic tilt at initiation of STS movement. Poor starting posture to initiate STS may impair the transfer of body mass upward in a vertical direction. Stroke patients initiate STS by excessive flexion of the trunk. This decreased the hip extension moment and stroke patients may depend on knee extension moment to stand up. To efficiently perform STS, the pelvis has to tilt anteriorly to flex the hip joint and the trunk to use the hip extension moment, reduce the knee extension moment and project the center of mass (COM) into the BOS [29].

Two basic strategies are used to transfer from sitting to standing: momentum-transfer strategy and zeromomentum strategy [4]. The momentum-transfer strategy involves producing forward momentum as the trunk and head translate anteriorly by the flexion at the hips causing the COM to shift toward and over BOS (the feet). This is followed by a strong concentric contraction of the lower extremities extensor muscles to lift the body off the sitting surface. The zero-momentum strategy involves excessive forward flexion of the trunk until the COM is within the BOS (the feet) prior to seat-off. Due to lacking of anterior pelvic tilt, stroke patients may also use this strategy in attempting to transfer and shift weight anteriorly. Poor alignment of the head and trunk with the pelvis in preparation to seat off may contribute to decrease the antigravity extensor activity of the lower limbs.

During initiation and mid of STS movement, the results of the current study showed a significant decrease of anterior pelvic tilt angle of the most affected side compared with less affected side of each patient in right hemiparetic group only. There was a non-significant difference of anterior pelvic tilt angle of the most affected side comparing with less affected side of each patient in left hemiparetic and control groups. The significant reduction of anterior pelvic tilt may be showed in GIa only as it was found that humans are generally right leg dominant for mobilization tasks but left leg dominant for tasks requiring postural stabilization [30]. The results may be due to stroke leads to bilateral weakness of the abdominal muscles with the weakness more pronounced in the most affected side. It was stated that, posterior

Table 4 Mean values of time of five repetitions sit to stand test in three groups

\begin{tabular}{lllllll}
\hline Variable & $\begin{array}{l}\text { Gla } \\
(\text { mean } \pm \text { SD) }\end{array}$ & $\begin{array}{l}\text { Gll } \\
(\text { mean } \pm \text { SD) }\end{array}$ & $P$ value & $\begin{array}{l}\text { Glb } \\
(\text { mean } \pm \text { SD) }\end{array}$ & $\begin{array}{l}\text { Gll } \\
(\text { mean } \pm \text { SD) }\end{array}$ \\
\hline Time of 5xSTS test (Seconds) & $19.77 \pm 5.99$ & $9.00 \pm 0.94$ & $0.0001^{*}$ & $17.53 \pm 4.79$ & $9.00 \pm 0.94$ & $0.0001^{*}$ \\
\hline
\end{tabular}

5xSTS five repetitions sit to stand, SD Standard deviation, $P$ probability, Significant $P^{*}<0.05,{ }^{\circ}$ Degree 
rotation of the pelvis on the most affected side is the commonest observational finding seen in stroke [9]. The results of the present study may be also attributed to the asymmetrical weight bearing of stroke patients. Stroke patients cannot bear and transfer weight equally during rising up from a sitting position. The patients have to compensate by using the less affected side. Alternation of pelvic alignment may contribute to decrease weight acceptance on the most affected lower limb [31]. Pelvic malalignment may contribute for asymmetric weight distribution on most affected lower limb during gait in stroke patients [32].

Time of five repetitions sit to stand test showed a significant increase in the current study in both stroke groups compared with control group. This may be attributed to stroke patients delay the initiation of the STS movement due to lacking of anterior pelvic tilt movement. Patients also initiate STS in the wrong direction by excessively increase the forward trunk movement. Due to the posterior pelvic position and increased thoracic kyphosis, patients may become unable to fully shift weight forward and take a longer duration to rise from a seated position. The results of this study agreed with Otao and colleagues [33] who concluded that the ability to anteriorly tilt the pelvis in patients with stroke during active exercise may be related to basic movements, such as the STS movement. The results of this study are also in agreement with Hitoshi and colleagues [10] who concluded that pelvic anteversion appears to be an important factor for patients to regain the ability to perform the STS movement.

\section{Conclusion}

The present study highlighted the importance of the assessment of pelvic tilt angles in stroke patients. The results of this study suggest that there is a relationship between sagittal pelvic angles and basic functional movements in stroke patients. Inability to tilt the pelvis anteriorly in stroke patients has a significant impact on ability to transfer from sitting to standing. This study attracted the attention to the importance of normal pelvic alignment and pelvic control exercises to improve the stroke patients functioning. There are very few studies on pelvic tilt angles and its effect on sit to stand task in stroke literature. Future studies are needed to address this gap aiming to improve the stroke patients' treatment, functioning, and quality of life.

\footnotetext{
Abbreviations

STS: Sit to stand; APT: Anterior pelvic tilt; PPT: Posterior pelvic tilt; 2D: Two dimensionalPALMPalpation meter; ASIS: Anterior Superior lliac Spine; PSIS: Posterior Superior lliac Spine; LOG: Line of gravity; COG: Center of gravity; BOS: Base of support; COM: Center of mass
}

Acknowledgements

Not applicable

\section{Authors' contributions}

All the authors contributed to the design of the study. SA did the neurological examination and selected the patients. MH and ME did the practical part: the assessment of pelvic inclination angles during sitting position and during STS movement. Data were pulled by all the authors in one master sheet. HA contributed in data analysis and all of authors contributed in the paper conception and editing. All authors reviewed and approved the final manuscript.

Funding

None.

Availability of data and materials

The datasets used and analyzed during the current study is not publicly available due to institutional rules.

\section{Ethics approval and consent to participate}

An informed written consent was obtained from all patients before being enrolled in the study. The study was approved by the ethical committee of Faculty of Physical Therapy, Cairo University, Egypt. Ethical committee number: (P.T.REC/012/001363). Date: (04/09/2016).

Consent for publication

Not applicable

Competing interests

The authors declare that they have no competing interests.

\section{Author details}

${ }^{1}$ Department of Neuromuscular Disorder and Its Surgery, Faculty of Physical Therapy, Cairo University, Cairo 12612, Egypt. ²Department of Neurology, Faculty of Medicine, Cairo University, Cairo 11562, Egypt.

Received: 30 March 2019 Accepted: 18 November 2019

Published online: 19 December 2019

\section{References}

1. Adegoke B, Olaniyi O, Akosile C. Weight bearing asymmetry and functional ambulation performance in stroke survivors. Glob J Health Sci. 2012;4(2):8794.

2. Gbiri C, Olawale O, Isaac S. Stroke management: informal caregivers' burdens and strians of caring for stroke survivors. Ann Phys Rehabil Med. 2015;58(2):98-103.

3. Galli M, Cimolin V, Crivellini M, Campanini I. Quantitative analysis of sit to stand movement: experimental set-up definition and application to healthy and hemiplegic adults. Gait Posture. 2008;28(1):80-5.

4. O'Sullivan B, Schmitz T. Improving functional outcomes in physical rehabilitation. $2^{\text {nd }}$ ed. Philadelphia: F.A. Davis; 2010. p. 98, 138-145.

5. Pollock A, Baer G, Campbell P, Choo P, Forster A, Morris J, et al. Physical rehabilitation approaches for the recovery of function and mobility following stroke. Cochrane Database Syst Rev. 2014;4:CD001920.

6. Ken L. Physics and the art of dance, understanding movement: Oxford University Press; 2002.

7. Hamilton N, Luttgens K. Kinesiology: scientific bases of human motion. $10^{\text {th }}$ ed. Boston: Mc Graw Hill; 2002. p. 158-180, 470-494.

8. Gjelsvik B, Syre L. The Bobath concept in adult neurology, $2^{\text {nd }}$ ed. Stuttgart: Thieme; 2016. p. 141.

9. Karthikbabu S, Chakrapani M, Ganesan S, Ellajosyla R. Pelvic alignment in standing and its relationship with trunk control and motor recovery of lower limb after stroke. Neurol Clin Neurosc. 2017;5:22-8.

10. Hitoshi A, Hiroyuki T, Tomoyuki H, Pleiades T, Kanichirou M. Relationship between the ability to perform the sit-to-stand movement and the maximum pelvic anteversion and retroversion angles in patients with stroke. J Phys Ther Sci. 2015;27(4):985-8.

11. Daniel C, Henrique S, Ricardo L, Guilherme T. Reliability of sagittal pelvic position assessments in standing, sitting and during hip flexion using palpation meter. J Bodyw Mov Ther. 2014;18(2):210-4.

12. Kuo Y, Tully E, Galea M. Skin movement errors in measurement of sagittal lumbar and hip angles in young and elderly subjects. Gait Posture. 2008; 27(2):264-70. 
13. Tully E, Fotoohabadi M, Galea M. Sagittal spine and lower limb movement during sit-to-stand in healthy young subjects. Gait Posture. 2005;22(4):33845.

14. Nagaraj A, Krishnan P. Effect of hip abductors and lateral rotators strengthening exercises on knee valgus alignment among adolescents: a prospective study. Ind J Physiother Occupational Ther Int J. 2015;9(3):242-7.

15. Whitney S, Wrisley D, Marchetti G, Gee M, Redfern M, Furman J. Clinical measurement of sit-to-stand performance in people with balance disorders: validity of data for the Five-Times-Sit-to-Stand Test. Phys Ther. 2005;85(10): 1034-45.

16. El Tallawy H, Farghaly W, Badry R, Hamdy N, Shehata G, Rageh T, et al. Epidemiology and clinical presentation of stroke in Upper Egypt (desert area). Neuropsychiatr Dis Treat. 2015;11:2177-83.

17. Maeda K, Toyoda K, Minematsu K, Kobayashi S. Effects of sex difference on clinical features of acute ischemic stroke in Japan. J Stroke Cerebrovasc Dis. 2013;22:1070-5.

18. Kwon $\mathrm{Y}$, Heo J, Jeon $\mathrm{H}$, Min S, Jun J, Tack G, et al. Age-gender difference in the biomechanical features of Sit-to-Stand Movement. J Mech Med Biol. 2016;16(8).

19. Yamaguchi M, Morino S, Nishiguchi S, Fukutani N, Tashiro Y, Shirooka H, et al. Comparison of pelvic alignment among never-pregnant women, pregnant women, and postpartum women (pelvic alignment and pregnancy). J Women's Health Care. 2016;5:1.

20. Hitoshi A, Hiroyuki T, Tomoyuki H, Pleiades T, Kanichirou M. Age-related changes in maximum pelvic anteversion and retroversion angles measured in the sitting position. J Phys Ther Sci. 2014:26(12):1959-61.

21. Janssen W, Bussmann J, Selles R, Koudstaal P, Ribbers G, Stam H. Recovery of the sit-to-stand movement after stroke: a longitudinal cohort study. Neurorehabil Neural Repair. 2010;24(8):763-9.

22. Sibella F, Galli M, Romei M, Montesano A, Crivellini M. Biomechanical analysis of sit-to-stand movement in normal and obese subjects. Clin Biomech (Bristol, Avon). 2003;18(8):745-50

23. Yu-Jeong K, Minyoung S, II-Hun B, Taesik L. The effect of simulating a leglength discrepancy on pelvic position and spinal posture. Phys Ther Sci. 2015;27(3):689-91.

24. Martin M, Kessler M. Neurologic interventions for physical therapy. 2nd ed. St. Louis: Saunders Elsevier; 2007. p. 310-1.

25. O'Sullivan B, Schmitz T, Fulk G. Physical rehabilitation. 6th ed. Philadelphia: F. A. Davis; 2014. p. 673

26. Pathak S, Vijayakumar K, Nayak A, Kedambadi R. The relationship between pelvic alignment and trunk control in stroke subjects: a cross-sectional study. Int J Res Med Sci. 2014;2(4):1483-7.

27. Yu S, Park $\mathrm{S}$. The effects of core stability strength exercise on muscle activity and trunk impairment scale in stroke patients. J Exerc Rehabil. 2013;9(3): $362-7$.

28. Tanaka S, Hachisuka K, Ogata H. Muscle strength of trunk flexion-extension in post-stroke hemiplegic patients. Am J Phys Med Rehabil. 1998;77(4):28890.

29. Fujimoto M, Chou L. Dynamic balance control during sit-to-stand movement: an examination with the center of mass acceleration. J Biomech. 2012;45(3):543-8.

30. Velotta J, Weyer J, Ramirez A, Winstead J, Bahamonde R. Relationship between leg dominance tests and type of task. Portuguese J Sport Sci. 2011;11(Suppl. 2):1035-8.

31. Karthikbabu S, Chakrapani M, Ganesan S, Ellajosyula R. Relationship between pelvic alignment and weight-bearing asymmetry in community-dwelling chronic stroke survivors. J Neurosci Rural Pract. 2016;7(Suppl. 1):37-40.

32. Patterson K, Parafianowicz I, Danells C, Closson V, Verrier M, Staines W, et al. Gait asymmetry in community-ambulating stroke survivors. Arch Phys Med Rehabil. 2008;89(2):304-10.

33. Otao H, Murata S, Hachiya M, Yumioka M, Ono T, Umei N, et al. Relationship between sitting of pelvic angles and basic movement of stroke patients. Jpn Health Promot Phys Ther. 2012;1:123-9.

\section{Publisher's Note}

Springer Nature remains neutral with regard to jurisdictional claims in published maps and institutional affiliations.

\section{Submit your manuscript to a SpringerOpen ${ }^{\circ}$ journal and benefit from:}

- Convenient online submission

- Rigorous peer review

- Open access: articles freely available online

- High visibility within the field

- Retaining the copyright to your article

Submit your next manuscript at $\boldsymbol{\nabla}$ springeropen.com 